UDC 316.356

LBC 60.54

\title{
DIGITAL LITERACY OF THE "THIRD AGE" GENERATION AS AN ADAPTIVE RESOURCE IN THE INFORMATION SOCIETY ${ }^{1}$
}

\author{
Olga A. Maksimova \\ Kazan Federal University, Kazan, Russian Federation
}

\begin{abstract}
The paper presents the analysis of the role of digital literacy in the adaptation of the "third age" generation to the conditions of the modern information society. It is noted that the formation of the information society and the spread of new digital technologies is a significant factor of socio-cultural transformations, affecting among other things, the generational dynamics of the modern Russian society. At the same time, the study of the processes associated with digitalization in modern conditions lags behind the needs of theory and practice.

Based on the analysis of the results of sociological research conducted within the framework of the project "Dynamics of real and conditional generations in the information, multi-confessional society (on the material of the Republic of Tatarstan)" with the use of quantitative and qualitative methodology, various parameters of the use of digital technologies by the older generation are revealed. It is noted that the generation of the "third age" in modern conditions feels the lack of knowledge in the field of digital technologies and recognizes the undisputed leadership in this area for the younger generations. At the same time, the results of the study show that the representatives of the "third age" generation for the most part actively increase their digital literacy and use it as an adaptation resource in the information society, as evidenced, among other things, by the dynamics of the use of the Internet by representatives of different generations from 2012 to 2017.

It is proved that digital literacy can promote activation of social position, improvement of quality of life, intensification of intergenerational and intra-generational interactions. Based on the analysis of empirical data, several most significant areas of such use are identified: digital technologies as a factor contributing to the activation of social interaction both at the macro-and micro-level of intergenerational interaction; as a possibility of manifestation of an active life position; as a mechanism for improving the quality of life of representatives of the "third age" generation.
\end{abstract}

Key words: generation of the "third age", digital literacy, digital technologies, information society, intergenerational interaction.

УДК 316.356

ББК 60.54

\section{ЦИФРОВАЯ ГРАМОТНОСТЬ ПОКОЛЕНИЯ «ТРЕТЬЕГО ВОЗРАСТА» КАК АДАПТАЦИОННЫЙ РЕСУРС В УСЛОВИЯХ ИНФОРМАЦИОННОГО ОБЩЕСТВА ${ }^{1}$}

\author{
Ольга Александровна Максимова \\ Казанский федеральный университет, г. Казань, Российская Федерация
}


териале Республики Татарстан)» с применением количественной и качественной методологии, выявлены различные параметры использования старшим поколением цифровых технологий. Отмечается, что поколение «третьего возраста» в современных условиях ощущает недостаток знаний в области использования цифровых технологий и признает бесспорное лидерство в данной сфере за молодыми поколениями. При этом результаты исследования показывают, что большинство представителей данной возрастной категории активно повышает свою цифровую грамотность и используют ее в качестве адаптационного ресурса в условиях информационного общества, о чем свидетельствует представленная динамика использования сети Интернет представителями разных поколений с 2012 по 2017 год.

Обоснованно, что цифровая грамотность может способствовать активизации социальной позиции, улучшению качества жизни, интенсификации межпоколенных и внутрипоколенных взаимодействий. На основе анализа эмпирических данных выделены несколько наиболее значимых направлений такого использования: цифровые технологии как фактор, способствующий активизации социального взаимодействия как на макро-, так и на микроуровне межпоколенческого взаимодействия; как возможность проявления активной жизненной позиции; как механизм повышения качества жизни представителей поколения «третьего возраста».

Ключевые слова: поколение «третьего возраста», цифровая грамотность, цифровые технологии, информационное общество, межпоколенческое взаимодействие.

Последняя треть XX в. охарактеризовалась кардинальными трансформациями во всех сферах жизнедеятельности общества. Существенные изменения произошли и в поколенческой структуре социума. В частности, в период 1970-1980-х гг. во многих странах фиксировались важные сдвиги в представлении о пожилых людях как о социально-демографической группе, испытывающей негативное воздействие проблемы одиночества после выхода на пенсию и вынужденного, не заполненного ничем досуга. В этот период в исследованиях западных авторов сформировался принципиально новый дискурс, иначе анализирующий данную социальную проблему. Е. Шанас отмечала: «Многочисленные свидетельства пенсионеров из разных стран показали, что они ничего не утратили с потерей своей работы или что они потеряли только доход. Тот факт, что промышленные рабочие во многих странах говорят о более раннем выходе на пенсию, должен показать нам, что необязательно социальная активность снижается с выходом на пенсию» [6, с. 114].

Люди пожилого возраста, вышедшие на пенсию, становятся объектом большого количества исследований. Появляются работы, анализирующие активный образ жизни, который можно вести на пенсии (особенно для представителей среднего класса). В конце 1980-х гг. была опубликована знаковая работа П. Ласлетта о разделении когорты пожилых на представителей «третьего» и «четвертого» возраста.
П. Ласлетт аргументировал свою точку зрения, согласно которой поколение «третьего возраста» не имеет четко определенного возрастного диапазона. В качестве отправной точки вступления в данное поколение он выделял начало официально установленного пенсионного возраста, а окончание связывал с потерей пожилым человеком дееспособности, которая, в случае ее наступления, характеризует переход к «четвертому возрасту». «Третий возраст», по его мнению, является своеобразной кульминацией или даже расцветом человеческой жизни, поскольку именно на этом этапе индивид освобождается от обязанностей содержать семью и зарабатывать на жизнь. Это период личностной самореализации, который характеризуется большей свободой, меньшей ответственностью и сохранением при этом различных жизненных целей [5]. В связи с этим возникла необходимость изменения отношения общества к населению «третьего возраста», которое предполагало бы восприятие его не как когорты дожития, а как активной, имеющей определенные интересы и ценности социальной группы.

За последние двадцать лет структурнофункциональная организация российского социума существенно изменилась под воздействием рынка, научно-технического прогресса, социокультурных трансформаций, развития информационно-коммуникационных технологий. Значимым фактором этих изменений выступает распространение новейших цифровых технологий, которые вносят множество принципиально новых характеристик в социальный 
ландшафт российского общества. Среди них: появление новых типов социальных отношений и практик, основанных на обезличенном виртуальном участии, формирование новых типов неравенств и социальных ролей, роботизация и автоматизация общественных сфер, виртуализация инфраструктуры в городах, сетевизация общества. При этом исследование процессов цифровизации российского общества в современных условиях явно отстает от потребностей теории и практики.

В контексте развития информационного социума актуализируется еще одна проблема, связанная с наличием цифрового разрыва между молодыми и старшими поколениями. Как отмечает О.В. Волченко, «базовым основанием для цифрового неравенства является наличие доступа к всемирной информационной сети, однако оно далеко не всегда может отразить реальные формы неравенства, существующие в сфере информационных технологий» [1, с. 166]. М. Хилберт выделяет три формы цифрового неравенства: доступ к информационным ресурсам, который зависит от экономического развития одной страны/региона, а также от экономического статуса конкретных индивидов; степень интенсивности и дифференцированности использования информационно-сетевых ресурсов и влияние Интернета на поведение и установки конкретных индивидов [4]. Именно во второй и третьей формах, на наш взгляд, наиболее остро проявляется цифровое неравенство между молодыми поколениями и поколением «третьего возраста»: при наличии практически повсеместного доступа к Интернету в современном российском обществе использование его пожилыми людьми остается крайне ограниченным.

При этом согласно данным, приводимым Е.Д. Мокрогуз на основе анализа статей западных авторов, «вопреки существующим в обществе представлениям о технофобии старшего поколения, неприятии технических новшеств, многочисленные исследования не выявили негативных установок, а, наоборот, продемонстрировали готовность пожилых людей с энтузиазмом осваивать компьютер, значительную внутреннюю мотивацию, высокий уровень настойчивости и целеустремленности в обучении» $[3$, с. 138$]$.
В апреле - мае 2017 г. исследовательским коллективом при непосредственном участии автора проведено комплексное социологическое исследование, посвященное анализу динамики поколений в современном российском обществе. Методология исследования включала в себя: репрезентативный опрос населения Республики Татарстан ( $N=1480$ чел.); глубинные интервью с представителями различных поколений татарстанцев $(N=20)$ и нарративные эссе представителей молодого поколения $(N=750)$. Одна из задач проекта состояла в определении специфики цифрового разрыва между разными поколениями, а также в анализе возможных вариантов использования цифровых технологий в межпоколенческом взаимодействии на микроуровне, в семье.

Результаты массового опроса показали, что наблюдается обратная зависимость между возрастом респондентов и частотой использования ими сети Интернет. В то же время сравнение материалов опроса 2017 г. с данными, полученными нами в 2012 г. [2, с. 7], демонстрирует безусловную позитивную динамику в степени вовлеченности старших поколений в практику использования сети Интернет (см. табл. 1).

Из представленных данных видно, что за прошедшие пять лет количество представителей старших возрастных когорт, использующих Интернет каждый день, увеличилось в два раза и даже более. Доля респондентов раннего пенсионного возраста (55-64 лет) возросла с 20,4 до $53,6 \%$, а среди 65 -летних и старше - с 5 до 13,7 \%. Одновременно сократилось количество представителей «третьего возраста», практически не использующих Интернет. Причем среди 55-64-летних таковых осталось менее пятой части $(19,6 \%)$, тогда как в 2012 г. их численность приближалась к половине $(48,5 \%)$. Несмотря на то, что в группе 65-летних динамика не столь впечатляющая (около $10 \%$ ), тем не менее она также свидетельствует о сокращении цифрового разрыва на поколенческом уровне.

Старшее поколение чаще выходит в сеть Интернет со стационарных компьютеров и ноутбуков, тогда как молодежь все больше предпочитает для этой цели мобильные устройства. Отметим, что вопрос носил неальтернативный 
характер и давал возможность выбора нескольких вариантов ответов (табл. 2).

Согласно полученным данным практически все представители молодого поколения используют мобильный телефон для выхода в Интернет, тогда как среди старших поколений таких лишь около половины.

Следует отметить, что использование мобильного телефона становится все более распространенной практикой цифровизации во всех возрастных группах. Однако и здесь наблюдается корреляция по возрастному признаку (табл. 3).

Если среди молодежи и респондентов среднего возраста (до 54 лет) наблюдается практически стопроцентное использование мобильных телефонов на постоянной основе, то в группе 55-64-летних таких пользователей 78,3\%, а среди тех, кто старше 65 лет, лишь половина $-53,5$ \%. В то же время $41,4 \%$ представителей «третьего возраста» отметили, что используют мобильный телефон время от времени. А совсем не пользующихся данным видом цифровой техники оказалось лишь 5,1 \%. Таким образом, в отличие от компьютеров и Интернета, мобильные телефоны в настоящее время используются практически всеми.

В целом представленные данные свидетельствуют о том, что поколение «третьего возраста» все чаще использует цифровые ресурсы в своих повседневных практиках. В этой связи актуализируется вопрос о специфике этого использования на индивидуальном уровне.

Таблица 1

Частота использования представителями разных поколений сети Интернет: динамика с 2012 по 2017 г. (в \%, к числу опрошенных по каждой возрастной категории)

\begin{tabular}{|l|l|r|r|r|r|r|r|}
\hline \multirow{2}{*}{$\begin{array}{c}\text { Частота использования } \\
\text { сети Интернет }\end{array}$} & \multicolumn{5}{|c|}{ Возраст респондентов (лет) } \\
\cline { 3 - 8 } & $16-24$ & $25-34$ & $35-44$ & $45-54$ & $55-64$ & $\begin{array}{c}65 \text { лет } \\
\text { старше }\end{array}$ \\
\hline \multirow{2}{*}{ Ежедневно } & 2012 г. & 83,1 & 72,7 & 43,3 & 32,2 & 20,4 & 5,0 \\
\cline { 2 - 8 } & 2017 г. & 93,3 & 90,3 & 85,6 & 61,5 & 53,6 & 13,7 \\
\hline \multirow{2}{*}{ Несколько раз в неделю } & 2012 г. & 12,1 & 10,8 & 18,1 & 13,4 & 10,8 & 8,9 \\
\cline { 2 - 8 } & 2017 г. & 2,1 & 6,8 & 6,6 & 12,6 & 10,0 & 3,8 \\
\hline \multirow{2}{*}{ Изредка } & 2012 г. & 2,6 & 11,5 & 23,3 & 27,4 & 20,4 & 10,9 \\
\cline { 2 - 8 } & 2017 г. & 3,4 & 2,3 & 7,0 & 17,2 & 16,7 & 16,6 \\
\hline $\begin{array}{l}\text { Практически не пель- } \\
\text { зуются Интернетом }\end{array}$ & 2012 г. & 2,2 & 5,0 & 15,2 & 27,0 & 48,5 & 75,2 \\
\cline { 2 - 8 } & 2017 г. & 1,3 & 0,6 & 0,8 & 8,8 & 19,6 & 65,9 \\
\hline
\end{tabular}

Таблицуа 2

Предпочитаемые устройства, используемые респондентами для выхода в Интернет (в \%, к числу ответивших по каждой возрастной категории)

\begin{tabular}{|l|r|r|r|r|r|r|}
\hline \multirow{2}{*}{$\begin{array}{c}\text { С каких устройств обычно } \\
\text { выходят в Интернет }\end{array}$} & \multicolumn{5}{|c|}{ Возраст респондентов (лет) } \\
\cline { 2 - 7 } & $16-24$ & $25-34$ & $35-44$ & $45-54$ & $55-64$ & $\begin{array}{c}65 \text { лет } \\
\text { и старше }\end{array}$ \\
\hline Со стационарного компьютера & 27,5 & 36,8 & 54,7 & 57,5 & 59,8 & 51,7 \\
\hline С ноутбука, планшета & 39 & 46,1 & 43,4 & 35,4 & 41,4 & 31,5 \\
\hline С мобильного телефона & 93,6 & 94,8 & 74,0 & 71,2 & 51,1 & 41,6 \\
\hline
\end{tabular}

Таблича 3

Частота использования респондентами мобильного телефона (в \%, к числу ответивших по каждой возрастной категории)

\begin{tabular}{|l|r|r|r|r|r|r|}
\hline \multirow{2}{*}{$\begin{array}{c}\text { Пользуетесь ли Вы } \\
\text { мобильным телефоном? }\end{array}$} & \multicolumn{6}{|c|}{ Возраст респондентов (лет) } \\
\cline { 2 - 7 } & $16-24$ & $25-34$ & $35-44$ & $45-54$ & $55-64$ & $\begin{array}{c}65 \text { лет } \\
\text { и старше }\end{array}$ \\
\hline Да, постоянно & 95,4 & 98,4 & 95,3 & 91,5 & 78,3 & 53,5 \\
\hline Да, время от времени & 4,2 & 1,0 & 4,7 & 8,1 & 17,9 & 41,4 \\
\hline Нет, не пользуюсь & 0,4 & 0,6 & 0,0 & 0,4 & 3,8 & 5,1 \\
\hline
\end{tabular}


Для того, чтобы ответить на него и понять, способствуют ли цифровые технологии повышению уровня социальной активности и адаптированности старшего поколения к условиям информационного общества, обратимся к анализу материалов, полученных с применением качественных методов исследования.

Результаты исследования показали, что существует достаточно прямая взаимосвязь между такими параметрами, как трудовая занятость индивида «третьего возраста» и его цифровая активность. Как правило, компьютер используется в рабочих целях: «B моей жизни я компьютеры использую только для профессиональной деятельности. То есть для проведения каких-нибудь расчетов, оформления каких-то документов или представление каких-то рисунков с известным пакетом программ по работе» (муж., 68 лет, работающий пенсионер). А прекращение трудовой деятельности влечет и отказ от использования этих ресурсов: «B последнее время, на работе, я работала на компьютере, конечно. Ну, до того, как на пенсию совсем ушла... А дома, вот в моей жизни, они занимают не самое большое место» (жен., 65 лет, не работающая пенсионерка).

В то же время распространение мобильного Интернета и совершенствование телефонных устройств способствует активизации цифровых практик старшего поколения: «С компьютером я, конечно, не дружу. Но... но в телефоне у меня есть Контакт! Я пользуюсь... вот только ВКонтакте у меня... пользуюсь в этом... в телефоне. А так у меня компьютера нет, но в телефоне есть... Можно выйти в Интернет» (жен., 62 года, не работающая пенсионерка).

Поколение «третьего возраста» все больше начинает осознавать, что цифровые технологии способствуют более комфортному существованию в условиях информационного общества. Отвечая на вопрос о том, для чего они чаще всего используют Интернет, респонденты старшего возраста с наибольшей распространенностью выбирали такие варианты, как просмотр новостей, поиск нужной информации, отправка электронных сообщений, общение в социальных сетях и мессенджерах. Пока еще достаточно редко цифровые технологии используются ими для оплаты счетов, осуществления покупок через Интернет. Освоить подобные практики им оказывается достаточно сложно. Однако в данном направлении активно используется ресурс межпоколенческих взаимодействий: «У меня сноха... Вот она большой специалист в компьютеpax. Очень мне помогает всегда. Счета по дому оплатить, за газ, за свет... Перевести мне деньги со сберкнижки на карточку. Это все она. Я ей звоню из деревни, она все по компьютеру мне делает. Очень удобно. Раньше ехать надо было в город, в банк, a теперь никаких забот у меня» (муж., 73 года, не работающий пенсионер).

Тот же информант рассказал об использовании возможности решения определенных жизненных проблем с использованием цифровых технологий: «Да, компьютер, Интернет - это очень полезные вещи... Вот у меня случай был. Мне слуховой аппарат положен, тугоухость у меня. Чтобы его получить, надо пройти врача, сурдолога, который один на весь город. Записаться по телефону невозможно к нему. Запись только на неделю, утром открывается, звонишь-звонишь, все занято. Потом как номер освободится, мест уже нет. Вот я так долго мучился, а потом сноха моя написала жалобу в Минздрав наш, через Интернет. Так мне тут же, через несколько дней, позвонили из больниць, пригласили на прием, все организовали. Через месяи наконеи aпnарат получил. А до этого год с места не двигалось... Вот жалко, сам так не умею я, мозги уже не те, чтоб учиться...» (муж., 73 года, не работающий пенсионер).

Результаты исследования показывают, что взаимодействия внутри семьи, связанные с использованием цифровых технологий, зачастую приобретают характер межпоколенческих эмоциональных трансфертов, имеющих, как правило, восходящую (от младших поколений к старшим) направленность. Об этом свидетельствуют повествования в нарративных эссе представителей молодого поколения: «Для наших родителей тяжело освочть современный мир, но мы должны им помочь в этом. Так же, как они учили нас ходить, разговаривать, правильно держать ложку, мы должны научить их работать с современными технологиями, 
которые упрощают нашу жизнь. Например, в намей семье я помогала маме освоить Интернет, искать нужную информаичию. Да было нелегко, трудно, но теперь она без труда находит всю информацию. Я редко приезжаю домой, но благодаря современным технологиям мы можем общаться, разговаривать по скайпу» (18 лет, жен).

Младшие поколения современного общества характеризуются исследователями как «цифровые аборигены», то есть рожденные в условиях цифровой реальности, ставшей для них привычной средой существования. Цифровое поколение фактически выполняет функцию проводника, учителя для старших поколений, не владеющих навыками работы с цифровыми ресурсами. Таким образом, цифровая грамотность младшего поколения становится не только фактором разобщенности, разрыва между поколениями на внутрисемейном уровне, но и, напротив, выступает в роли ресурса взаимодействия, активизируя эмоциональные межпоколенческие трансферты по восходящей линии, способствуя укреплению связей между младшим поколением (внуков) и поколением «третьего возраста» (прародителей). Кроме того, цифровое поколение, осознавая всю сложность освоения информационных средств старшими поколениями, готово оказывать всяческую помощь и поддержку: "Стариим поколениям, особенно нашим бабушкам и дедушкам, очень сложно осваивать всю эту технику. Но главное в нашем деле - это терпение. Вот моей бабушке уже 76 лет. Она может ответить на звонок по мобильному и даже набрать номер из списка контактов, но смс-ки отправлять у нее никак не получалось. Вот я ее терпеливо учил-учил. Больше года. Так знаете, сколько было радости, когда однажды утром я получил смс с ее номера с текстом: внучокприходизавтракать. Слитно все слова были написаны. Но я же понял. А мы в соседних домах живем. Побежал сразу к ней. Потом и пробель научил ее ставить. Теперь очень горжусь $и$ ею, $u$ самим собой. Мы с ней это вместе сделали» (муж., 22 года); «Бабушки и дедушки наши очень тяжело осваивают все эти новинки техники - компьютеры, планшеты, телефоны мобильные. Но для этого у них и есть внуки, чтобы всему научили! Я никогда своим не отказываю в помощи, хотя иногда бывает непросто все растолковать» (жен., 21 год).

Использование Интернета как средства общения с родственниками, живущими территориально далеко, согласно полученным данным является одним из наиболее важных мотиваторов, способствующих освоению поколением «третьего возраста» цифровых технологий: «Все-таки Скайп это великое изобретение! Я долго не мог освочть его, сын помогал. Но когда вот уже наладили там контакты, теперь все просто. Я смог увидеть и пообщаться с родственниками, которых по 20 лет и больше даже не видел. Раньше, в советское время, сами моложе были, да и недорого было... Сел на самолет, слетал к родным на другой конеи странbl. А сейчас вот Скайп эти поездки заменяет» (муж., 76 лет, работающий пенсионер).

Можно отметить в целом, что активность пожилых людей в процессе освоения цифровых технологий в настоящее время достаточно высокая, что отмечают и представители молодежи: «Старшее поколение с интересом осваивает различные гаджеты, соииальные сети, без особых трудностей работают в сети Интернет, стараясь не отставать от своих внуков и быть на одной волне. Например, моя бабушка в семьдесят лет прошла курсы компьютерной грамотности для пожилых людей. Таким образом, обладая мудростью, старшее поколение передает жизненный опыт своим внукам, а те, в свою очередь, посвящают их в современные технологии» (муж., 18 лет).

По итогам можно констатировать, что в современных условиях поколение «третьего возраста» все активнее повышает свою цифровую грамотность и использует ее в качестве адаптационного ресурса в условиях информационного общества. Можно выделить несколько наиболее значимых направлений такого использования.

1. Цифровые технологии как фактор, способствующий активизации социального взаимодействия. Интернет предоставляет возможности для взаимодействия представителей старшего поколения с родственниками, знакомыми, что особенно актуально в слу- 
чае их значительной территориальной удаленности. Кроме того, активизируется и межпоколенческое взаимодействие внутри семьи, налаживаются эмоциональные трансферты. Данный фактор способствует минимизации чувства одиночества, особенно в ранний пенсионный период, когда меняющий свой социальный статус индивид особенно остро нуждается в формировании новых каналов взаимодействия взамен утраченных.

2. Возможность проявления активной жизненной позиции. Использование цифровых технологий лично или опосредованно, через более молодых помощников, позволяет пожилому человеку добиться решения своих жизненных проблем, почувствовать собственную значимость, снизить ощущение бессилия, безвыходности в той или иной ситуации. Освоение хотя бы элементарных навыков владения цифровыми технологиями позволяет им повысить уровень самооценки и, как следствие, обрести больший психологический комфорт.

3. Повышение качества жизни. Использование современных информационно-сетевых ресурсов позволяет осуществлять онлайн-платежи, получать услуги государственных учреждений и общественных организаций в режиме онлайн, участвовать в виртуальных сообществах, иметь оперативный доступ к различной информации. Все эти возможности также служат ресурсом для адаптации поколения «третьего возраста» к специфике информационного общества, позволяя активно использовать возможности, предоставляемые новой реальностью.

\section{ПРИМЕЧАНИЕ}

${ }^{1}$ Статья подготовлена при финансовой поддержке Российского Фонда фундаментальных исследований (РФФИ) в рамках научного проекта № 17-06-00474 «Динамика реальных и условных поколений в информационном, полиэтноконфессиональном обществе (на материале Республики Татарстан)».

\section{СПИСОК ЛИТЕРАТУРЫ}

1. Волченко, О. В. Динамика цифрового неравенства в России / О. В. Волченко // Мониторинг общественного мнения: Экономические и социальные перемены. - 2016. - № 5. - С. 163-182.
2. Максимова, О. А. «Цифровое» поколение: стиль жизни и конструирование идентичности в виртуальном пространстве / О. А. Максимова // Вестник Челябинского государственного университета. Филология. Искусствоведение. - 2013. № 22 (313), вып. 81. - С. 6-10.

3. Мокрогуз, Е. Д. Обучение людей третьего возраста основам компьютерных технологий: обзор исследований / Е. Д. Мокрогуз // Вестник Адыгейского государственного университета. Серия 3 : Педагогика и психология. - 2015. - № 3 (162). C. $138-148$.

4. Hilbert, M. Digital gender divide or technologically empowered women in developing countries? A typical case of lies, damned lies, and statistics / M. Hilbert // Women's Studies International Forum. Pergamon. - 2011. - Vol. 34, № 6. - P. 479-489.

5. Laslett, P. A fresh map of life: The emergence of the third age / P. Laslett. - L. : Weidenfeld and Nicolson, 1989. $-213 \mathrm{p}$.

6. Shanas, E. Disengagement and Work: Myth and Reality / E. Shanas. - N.Y. : International Center of Social Gerontology,1971. -315 p.

\section{REFERENCES}

1. Volchenko O.V. Dinamika tsifrovogo neravenstva $v$ Rossii [Dynamics of Digital Inequality in Russia]. Monitoring obshchestvennogo mneniya: Ekonomicheskie i sotsialnye peremeny, 2016, no. 5, pp. 163-182.

2. Maksimova O.A. «Tsifrovoe» pokolenie: stil zhizni i konstruirovanie identichnosti v virtualnom prostranstve [Digital Generation: Lifestyle and Construction of Identity in the Virtual Space]. Vestnik Chelyabinskogo gosudarstvennogo universiteta, 2013, no. 22 (313), pp. 6-10.

3. Mokroguz E.D. Obuchenie lyudey tretyego vozrasta osnovam kompyuternykh tekhnologiy: obzor issledovaniy [Teaching the Basics of Computer Technology to People of the Third Age: a Survey of Research]. Vestnik Adygeyskogo gosudarstvennogo universiteta. Seriya 3: Pedagogika i psikhologiya, 2015, no. 3 (162), pp. 138-148.

4. Hilbert M. Digital gender divide or technologically empowered women in developing countries? A typical case of lies, damned lies, and statistics. Women's Studies International Forum. Pergamon, 2011, vol. 34, no. 6, pp. 479-489.

5. Laslett P. Afresh map of life: The emergence of the third age. London, Weidenfeld and Nicolson, 1989. 213 p.

6. Shanas E. Disengagement and Work: Myth and Reality. NY, International Center of Social Gerontology, 1971. 315 p. 


\section{СОЦИОЛОГИЯ И СОЦИАЛЬНЫЕ ТЕХНОЛОГИИ}

\section{Information about the Author}

Olga A. Maksimova, Candidate of Sciences (Sociology), Associate Professor of Department of General and Ethnic Sociology, Kazan Federal University, Kremlevskaya St., 18, 420008 Kazan, Russian Federation, OAMaksimova@kpfu.ru.

\section{Информация об авторе}

Ольга Александровна Максимова, кандидат социологических наук, доцент кафедры общей и этнической социологии, Казанский федеральный университет, ул. Кремлевская, 18, 420008 г. Казань, Российская Федерация, OAMaksimova@kpfu.ru. 